\title{
Erratum to: The Knowledge of Effective Parenting Scale (KEPS): A Tool for Public Health Approaches to Universal Parenting Programs
}

\author{
Leanne Winter • Alina Morawska • \\ Matthew Sanders
}

Published online: 2 September 2014

(C) Springer Science+Business Media New York 2014

\section{Erratum to: J Primary Prevent (2012) 33:85-97 DOI 10.1007/s10935-012-0268-x}

An author (Matthew Sanders) of the original publication wishes to include the following:

Conflict of interest The Triple P-Positive Parenting Program is owned by the University of Queensland. The University through its main technology transfer company, Uniquest Pty Ltd, has licensed Triple P International Pty Ltd to publish and disseminate the program worldwide. Royalties stemming from published Triple $\mathrm{P}$ resources are distributed in accordance with the University's intellectual property policy and flow to the Parenting and Family Support Centre; School of Psychology; Faculty of Health and Behavioural Sciences; and contributory authors. No author has any share or ownership in Triple P International Pty Ltd. Matthew Sanders is the founder and an author of various Triple $\mathrm{P}$ programs and a consultant to Triple $\mathrm{P}$ International. Alina Morawska is an author of various Triple $\mathrm{P}$ programs.
The online version of the original article can be found under doi:10.1007/s10935-012-0268-x.

L. Winter $(\bowtie) \cdot$ A. Morawska $\cdot$ M. Sanders

School of Psychology, Parenting and Family Support Centre, The University of Queensland, Brisbane 4072, Australia

e-mail: 1.winter@uq.edu.au 